\title{
Youth Sport: A Frontier in Education
}

\author{
David Littlefair* and David Nichol \\ Department of Social Work, Education and Community Wellbeing, Faculty of Health and Life Sciences, Northumbria \\ University, Newcastle upon Tyne, United Kingdom
}

Children are encouraged to participate in sport (Allender et al., 2006), through the school curriculum and specific dedicated clubs. Such provision can be described as a frontier in education with the role of the facilitator or "teacher" usually being undertaken by a coach. However, the experiences of those in involved in this type of informal learning environment are not well-researched or documented. Therefore, the aim of this study is to gain an insight into the experiences of children and stakeholder adults in such a setting. This study analyses and assesses the reality of the learning experience from the perspectives of the key stakeholders, children, coaches, and parents through their involvement in a particular youth cricket club. A qualitative approach was deployed, in the form of three separate focus groups for parents $(n=5)$, children $(n=10)$, and coaches $(n=3)$. At thematic analysis was conducted across the data set. Together with the coaches, who assume the role of a teacher, delivering learning, parents were included to take part in this study because they can be observers of the learning (unlike in mainstream education) and indirectly affect the learning through pseudo coaching. The children are involved as recipients of the learning and may view the coaches with a teacher identity. The study

OPEN ACCESS

Edited by:

Luiz Sanches Neto,

Universidade Federal Do Ceará, Brazil

Reviewed by:

Elisabete dos Santos Freire, Universidade São Judas Tadeu, Brazil Manpreet Kaur Bagga, Partap College of Education, India

*Correspondence: David Littlefair david.nichol@northumbria.ac.uk

Specialty section:

This article was submitted to Teacher Education,

a section of the journal

Frontiers in Education

Received: 26 June 2019 Accepted: 08 October 2019 Published: 23 October 2019

Citation: Littlefair D and Nichol D (2019) Youth Sport: A Frontier in Education. Front. Educ. 4:119 doi: 10.3389/feduc.2019.00119 highlighted a good development and learning environment within this particular youth cricket club and it alludes to a disparity within the wider field of youth sport. All three of the chosen groups, the players, parents, and coaches, have aligned successfully to create a supportive, non-threatening environment, to allow the children to learn, develop their confidence, self-esteem and skill. In contrast, all groups highlighted the difference of their experiences of youth football, where a more negative experience was identified, potentially due to the subculture or the stakeholders involved.

\section{Keywords: learning, teaching, development, coaching, youth sport, youth cricket}

\section{INTRODUCTION}

In relation to the promotion of sport and health, children, in particular, are encouraged to participate in sporting activities (Allender et al., 2006), usually through the school curriculum and often through specific dedicated sports clubs. Governing bodies have helped fund such provision and ensure governance at grass roots level (Sport England, 2016). Such provision is a frontier in education with the role of the teacher/educator usually undertaken by the coach. It is a learning setting with children working together and/or individually to develop their skills in a particular sport. Learning in physical education and sport is conceptualized in multiple ways (Quennerstedt et al., 2014). However, it is a practical and embodied method of learning and can be argued to link cognitive and practice learning (Quennerstedt et al., 2014).

Jeffs and Smith (2005) feel that a key task of youth workers is to create favorable learning environments including social and experiential facets. Although there are numbers of studies on different aspects of youth sports clubs such as Light et al. (2013) on why children join and stay in 
clubs, Whatman and Main (2018) on re-engaging youth at risk and Shaikh and Forneris (2018) on influence of coaches, there is limited research focussing on the experiences of the key stakeholders in this learning environment. Stewart and Jordan (2017) advocate that studies are needed regarding learning opportunities in informal contexts.

Given that experiences of facilitators and participants are well-researched and documented in formal regulated learning environments such as school, the question driving this research was what are the experiences of facilitators and participants in informal non-regulated learning environments?

Thus, this study investigates the experiences that children, coaches and parents have had through their involvement and engagement with a youth cricket club. It gains a valuable insight into the workings of those environments where children, of varying ability, are expected to develop their confidence, enthusiasm, and skills (Stafford, 2011). The paper analyses and assesses the reality of the teaching and learning experience from the perspectives of the key stakeholders, children, coaches, and parents.

\section{LITERATURE REVIEW}

Coaching as an activity in youth sport provides an opportunity for learning to take place outside the formal structure of an educational establishment and structure (Penney, 2006). Youth sports clubs can be places where an authoritarian approach to learning becomes the accepted norm (Cushion and Jones, 2006). However, this approach can jeopardize child learning and development and encourage a bullying culture (Reeve, 2009). If a goal of child participation in sport is to encourage lifelong involvement in physical activity then early learning experiences are of crucial importance (Kirk, 2005). Although the prior experience of the facilitator, in this case the coach, provides them with sports specific knowledge, they do bring with them the subculture of the sport (Lemyre et al., 2007). This socialization of the subculture could be positive or could reinforce negative stereotypes of practice.

Differences with mainstream school education include concentration on a single sport, not a broad curriculum, the depth with which parents can become involved and the training/qualifications of the facilitator/"teacher."

Youth sport can be seen as giving a deeper understanding of a sport due to the concentration on one sport and that children have chosen to engage ( $\mathrm{Na}, 2015)$. It is assumed that children participate in youth sport of their own volition (Romar et al., 2016). Parents can view this route as child choice and see their own role and involvement as instrumental (Na, 2015). However, in some circumstances children can be participating in sport to please the parent or are coerced by the parent and parental pressure can place more stress on the child and take away the enjoyment (Donnelly, 1997). Parents views of sport can be colored by their own experiences (George and Curtner-Smith, 2016). It is essential that parents and children have the same aims for participation and for children to know that their parents understood their needs and experiences and act in a manner which manifested these outcomes (Knight and Holt, 2014).

The sport being undertaken by children can impact the experience of the children in such sport (Evans et al., 2017). Thus, there can be variations in experience based upon the choice of sport that children undertake. The type of sport can also make a difference to the learning situation for the coach (Lemyre et al., 2007). Youth leaders, such as coaches in this instance, do provide learning and learning situations for their children (Shaikh and Forneris, 2018).

Lemyre et al. (2007) suggest that although coaches can undergo training programmes it is only one method of their learning. Many coaches learn to coach through experience (Gilbert and Trudel, 2001). Coaches in general do recognize the importance of teaching a wide range of values and life skills to participants in youth sport (McCallister et al., 2000) but can face tensions related to their role in informal learning environments (Stewart and Jordan, 2017). In an ideal situation coaches should be identifying goals for student learning and developing student progress (Saunders et al., 2009) and should use a range of learning situations (Wright et al., 2007). Gilbert et al. (2009) advocates a learning community approach to coach development but acknowledges that most youth sport environments do not support professional development.

The traditional role of the coach is stereotyped as telling the participants what to do and the role of the participants is to listen, absorb, and comply (Lesyk and Kornspan, 2000; Romar et al., 2016) found that coaches want their participants to have fun, learn life skills, be part of a team, develop confidence, and have the excitement of competition. Providing the young participants with an ownership of their own participation will play a significant role in achieving some of these outcomes (Romar et al., 2016).

One of the key goals of youth sport is encouraging lifelong physical activity. Kirk (2005) argues that secondary school physical education programmes have in their traditional form been ineffective in promoting lifelong physical activity. If the activities and experiences of young people in youth sport are inherently pleasurable and intrinsically satisfying then there is a potential future participation (Kirk, 2006). Transformative physical education can provide a physical activity context within a nurturing and motivating environment (Ennis, 2017).

Most learning theories are defined cognitively and therefore they need to be adapted for sport and physical education contexts which involve practical learning embodiment and are influenced by culture and areas such as health (Quennerstedt et al., 2014). If learning theories are applied to sport that focus upon cognitive decision making, self-motivation, and personal meaning then this could support young people for a lifetime of physical education (Ennis, 2017).

This review suggests that Youth Sport settings are a learning environment with the coach in the role of the facilitator/teacher. However, studies do not tend to focus on the experiences of children and adult stakeholders in a particular environment to analyse this joint socio-learning interaction. 


\section{Aim and Focus of the Study}

The aim of the study was to examine this particular setting with regard to understanding how the teaching and learning environment for the children impacted upon their enjoyment and development together with the experiences of the stakeholder adults.

The focus for this study was a sports club in North East England, offering cricket at all levels from junior, under 11 to under 15's, through to senior level teams. Cricket training takes place once a week and, through the summer, league and cup games are played on a weekly basis. Through the winter, training continues one night per week. The club raises money through sponsorship from local businesses, the participants do not pay subs, but raise funds through enterprise activities, for example, BBQ's and race nights.

All of the coaches, are volunteers, however two are qualified cricket coaches and one a secondary school teacher, with no specific cricket qualifications. The club is short on resources overall, although this season, they raised enough money to build some outdoor training nets to help players further develop.

\section{METHODS}

Since there are limited studies in this field which explicitly focus upon key stakeholders at a single youth sports club, it was decided to apply a qualitative approach using the method of focus groups. Focus groups are considered a suitable tool to measure social knowledge and experience within a group, in particular in relation to a real life group setting (Morgan, 1997). The Focus group helped to facilitate the participants to share their thoughts, feelings and emotions about the youth sports club's learning environment. It was considered that this was the best approach given that engagement was with a single club with a particular sport. Although, findings cannot be generalized from such a study, it does provide an indicative insight into the environment and offers a way forward for future research. Regardless of the size, it is valuable information for the club in question to improve or review their existing practice. Children, parents and coaches from the club were chosen to take part in this study because they have all built up knowledge and experience from their involvement with youth cricket. The research was explained to the potential participants and volunteers were requested. This was deemed to be the best method in order to get a range of abilities and opinions.

The data was collected through discussion with three separate focus groups namely parents, children, and coaches. This enabled the drawing out the experiences of each group in their involvement in youth cricket and the wider field of youth sport. Each focus group lasted $\sim 20 \mathrm{~min}$. Focus groups are not perfect but do seem the most appropriate generator for the themes in this study. On the positive they can access group norms however they could also put pressure on members of the group out of step with the majority and encourage a concealment of view (Somekh and Lewin, 2005). Focus groups are useful for developing themes, orientating focus and empowering participants (Krueger,
1988; Morgan, 1988; Bailey, 1994; Robson, 2002; Cohen et al., 2007). Through the participant interaction the views of the participants rather than the researcher can emerge and thus their agenda can predominate (Cohen et al., 2007). On this basis the emerging themes were driven and formed by the children, parents and coaches.

The sample was from the under 15's age group. This group was chosen as they had 2 years' existing experience of the club and were of an age where they could reflect on their experiences. Volunteers were requested to ensure that the participants were comfortable and didn't feel any obligation or pressure and hopefully felt free to voice any opinions or concerns without comeback. From a group of 18 players, 10 volunteered to participate, 56\%. All three coaches volunteered to take part. They have a broad experience of coaching, having coached across different age groups, as per the policy of the club.

From the parents of the players, 5 parents volunteered to participate in the study a representation of $28 \%$ viewed from the perspective of 18 players. Morgan (1988, p. 43), suggests "between 4 and 12 participants in a group," so the sampling size fell within this range for all groups bar the coaches but involvement of all 3 represented $100 \%$.

These focus groups were held at a local cricket club, within the North East, at their own premises, on an evening where training and practice had taken place. When delivering the focus group, it is essential to encourage positive group dynamics, spontaneity, confidentiality but also adhering to the research agenda (Somekh and Lewin, 2005). In particular, children need to be made to feel at ease and confident so holding a focus group in their own environment and having met the researcher at least on one occasion prior to the focus group is important. The researcher does need to engage with the group and does need to generate the initial data for the group as well as collecting the data (Somekh and Lewin, 2005). It is essential to ensure flexibility in order to allow the groups the opportunity to raise unexpected issues and information they felt relevant to the discussion. It is the interaction of the group that creates the data and the outcomes and will yield insights which may not have emerged otherwise (Cohen et al., 2007).

Initial themes drawn from literature and the Sport England strategy (Sport England, 2016) were used to stimulate discussion within the focus groups. Questions were asked about experiences of being part of the club and the participants were encouraged to share stories, emotions or feelings about their involvement with sport (Daiute and Lightfoot, 2004). Thematic analysis was applied to the subsequent data produced as it is a useful and flexible method for qualitative data (Braun and Clarke, 2006). Although themes drawn from the literature were used as the basic theoretical framework, new themes also emerged from the data, representing a partial grounded approach to the study.

The Focus groups were transcribed and then first order codes where applied across the three data sets. All these codes were then gathered into potential themes and the whole data set was checked again to ensure that all the codes and findings were represented. Finally, the themes were refined with clear definitions. 


\section{RESULTS}

A thematic analysis was applied to the data and the themes that emerged were, friendliness, inclusive participation, support and encouragement, a comparison to football and winning and losing.

\section{Friendliness}

One of the overarching themes to emerge from the data was that the cricket club involved was friendly and the children enjoyed playing for them. The children specifically mentioned that it was fun, relaxed, and sociable. One child stated, "it was a good laugh" and another remarked "I enjoy the social side of being a member of the club and fundraising was fun." None of the respondents referred to it as not being friendly.

\section{Inclusive Participation}

In particular, it was suggested that the game was not taken too seriously, as it was more about development, enjoyment, and ensuring everyone played a part. It also became clear that the players felt that the cricket club operated in an inclusive environment, with all players, regardless of gender or ability, having a chance to perform through batting and bowling. One child mentioned that "I enjoy cricket as I get picked" and another remarked that she "always gets a chance to bat and bowl."

The discussion raised by the coaches suggests that the ethos of the cricket club is one of development for the children. The coaches highlighted how the learning and development is tailored to ensure that all children are encouraged to enjoy the game, gain experience of all aspects of it and crucially, develop toward improving themselves both as a cricket player and team player.

The coaches outlined that they were short of finance and resources, however, they worked hard to ensure that this did not prevent them from creating an inclusive learning experience.

The parents were full of praise for the learning environment created by the coaches for their children. The parents provide an insight in their experience of youth cricket, explaining that they see it as a more relaxed, pleasant and inclusive sport, in an environment which aims to support the development of the players.

\section{Support and Encouragement}

The players also suggested that they felt supported at the cricket club through encouragement on the side lines from spectators, from their peers in the team and also from the coaching team. One remarked that "everyone encourages everyone else" and another stated that he found "not as much shouting from people on the side-lines, so much less pressure."

The coaches highlighted their desire to create the environment to facilitate the development of the players through their own experiences and enthusiasm for the club and sport. They encourage parental involvement in both the support of the players and also the running of the club. The parents seem to be very much lead by the learning environment created by the coaches and consequently fully subscribe to the ethos of this club.

\section{Comparison to Football}

Another theme to emerge was a comparison to football. Those children who had experience of playing football offered a comparison of the sports. Overall, football was deemed less inclusive, through it being more aggressive than cricket, more pressure on results and that it was based more on the ability of individual players. Of particular interest are the following quotes from the children, "Didn't like football as it's rough and aggressive, cricket is more fun, friendly and inclusive" and "in particular I felt under pressure at football to do well." This suggests that in this instance the experiences of a learning and developmental environment were better served in their cricket club than in other sports they had participated in. Other participants in the study agreed with these comments and suggested they enjoyed cricket more than football because it gave them the opportunity to play. Some children with experience of both sports highlighted the difference in the facilitator of learning and development, in this case the coach. One stated that "football focuses more on winning and performance, in cricket the coaches try to improve everyone, not just the better players."

The coaches also contrasted their experiences of this club with other sports clubs they have been engaged with. They offered an insight into proceedings at football clubs they have been involved in, whereby parental involvement can be a hindrance to the development. They suggested that in football, "it is more about the development of those children who show most potential and initial ability." Thus, the learning environment created by the coaches seems to be a crucial factor as it sets the ethos and creates the space for the development of the children.

Parents concur with the coaches in as far that they also share examples of youth football being an "aggressive" sport, where the supporters are continually shouting at the players and in one particular example provided, at the referee.

\section{Winning and Losing}

Although the children obviously enjoyed the more inclusive and friendly environment that is not to say that the players didn't want to win, indeed they did as they mentioned about "nothing negative except losing" and "season is harder because our better players moved up an age group, so we lose more." They also did allude to different attitudes with other cricket clubs for example they mentioned that they "play against some very good teams who take it seriously" and one said he "I used to play at another club, but felt it was so serious, they were only interested in the better players." This suggests that although the children felt that their particular cricket club provided a supportive learning environment that may not be the case for all cricket clubs and also other youth sports clubs such as football.

The coaches spoke about their ethos of participation being paramount to winning. They expanded on this through providing examples of pressure being applied to children playing football because of a "win at all costs" mentality.

Criticism of bad language at youth football was cited, as was the competitive nature of it, which can potentially discourage participation. Cricket however, was described as a sport where there was "not as much at stake and consequently, was more fun." 


\section{DISCUSSION}

It is apparent that in this particular cricket club the learning and development of the players is paramount and they undertake this in a supportive and inclusive environment. A commitment by coaches to learning and learners is seen as a fundamental aspect of good coaching (Penney, 2006). The coaches drive the ethos and this fits in with the findings of Lesyk and Kornspan (2000) that they want the players to have the key ingredients of fun, life skills, enjoyment, and teamwork. The fact that the children are enjoying the experience means they are far more likely to carry on playing sport into adulthood (Kirk, 2006). It does appear in this example that children all participate of their own volition, are not coerced by their parents and that they have the same aims for participation (Donnelly, 1997; Knight and Holt, 2014; Na, 2015; Romar et al., 2016). Maybe the parents views are colored by their own experiences (George and CurtnerSmith, 2016) as are the coaches (Lemyre et al., 2007). It was apparent to the coaches and parents that adults can have a negative aspect upon youth sport (Partridge and Wann, 2015). However, in this instance that experience is for the better as many have seen bad practice elsewhere and do not wish to emulate it. Thus, the two adult groups seem both keen to promote a positive environment which could be significant. A number of the players have also had experiences elsewhere and acknowledge that this club is an environment when ability does not matter and they can all develop their confidence and skills (Stafford, 2011) and this means the three stakeholders groups share the same ethos.

There is indicative evidence that all clubs are not necessarily the same as this one. Many of the negative experiences were related to football so it could be that the sport undertaken is a factor in the experience (Evans et al., 2017). However, there were also negative references to other cricket clubs so it may not be just purely down to the culture of the sport but maybe also to the ethos of the most powerful agents (Bourdieu, 1986), in this case the coaches, or the fact all stakeholder groups want the same ethos.

If enjoyment is indeed the key to participation (Kolt and Kirkby, 1996; Butcher et al., 2002; Allender et al., 2006; Cadeyrn et al., 2007) then this learning environment at this particular club seems to have found the right ingredients for growth and development. It aids the learning journey of the child by creating an environment of enjoyment, meaning and fun (Light et al., 2013).

\section{CONCLUSION}

This study has given an insight to the experiences of children and adult stakeholders in an informal learning setting. Although the focus of this study is on one particular club, therefore the findings cannot be generalized, what is apparent is that the children learn, have fun, gain valuable experience, and enjoy playing sport. It is an environment that enhances learning development which is crucial at a younger age (Kirk, 2005). It appears one of the main reasons for this is the lack of pressure placed on the children to perform and win. Hence, their experience of cricket is about playing and developing their skill in a supportive environment. This learning environment and ethos has been created by the coaches and allows for an inclusive feeling for all the children and development in that particular sport. In this instance all three of the chosen groups, the players, parents and coaches, have aligned successfully to create this supportive, nonthreatening environment, to allow the children to learn, develop their confidence, self-esteem, and skill. However, this research indicates that this learning environment and ethos could be undermined by one of the stakeholder groups. For example, in contrast to this positive experience, all the stakeholder groups highlighted a negative difference between this cricket club and their experiences of involvement with youth football.

Although this is only indicative the difference could be due to the subculture of the sport or the outlook and actions of the coaches, which appears paramount as the coaches seem to have the biggest influence. In this instance the other stakeholder groups in this club acquiesce to the ethos produced by the coaches but if they did not it could undermine the inclusive learning environment. Apparent here, is that one, more or all of the groups can intervene to create a more negative, highly pressured, and competitive environment, which according to our sample, would conspire to create a less enjoyable experience.

This study gives a brief glimpse into an informal learning environment at one particular youth cricket club. Further research would be necessary to ascertain patterns regarding individual sport subculture and the effect of stakeholder groups which would require a more in depth study with a larger number of Youth Sports Clubs.

It does seem indicative that a supportive learning environment is good for the well-being of the children and their development (Tharani et al., 2017). In this case study the stakeholders conspire to create a constructive, supportive and inclusive learning environment from which all stakeholder groups seem to benefit and enjoy.

\section{DATA AVAILABILITY STATEMENT}

The datasets generated for this study are available on request to the corresponding author.

\section{ETHICS STATEMENT}

The studies involving human participants were reviewed and approved by Northumbria University. Written informed consent to participate in this study was provided by the participants' legal guardian/next of kin.

\section{AUTHOR CONTRIBUTIONS}

DN and DL conceived of the presented idea. They both developed the theory and conducted the research and verified the analytical methods. All authors discussed the results and contributed to the final manuscript. 


\section{REFERENCES}

Allender, S., Cowburn, G., and Foster, C. (2006). Understanding participation in sport and physical activity among children and adults: a review of qualitative studies. Health Educ. Res. 21, 826-835. doi: 10.1093/her/cyl063

Bailey, K. D. (1994). Methods of Social Research, 4th Edn. New York, NY: The Free Press.

Bourdieu, P. (1986). Distinction. London: Routledge; Kegan Paul.

Braun, V., and Clarke, V. (2006). Using thematic analysis in psychology. Qual. Res. Psychol. 3, 77-101. doi: 10.1191/1478088706qp063oa

Butcher, J., Lindner, K. J., and Johns, D. P. (2002). Withdrawal from competitive youth sport: a retrospective ten-year study. J. Sport Behav. 25, 145-163.

Cadeyrn, J., Gaskin, B., and Garland, R. (2007). Occupying the crease: an exploration of youth cricket in New Zealand. Eur. Sport Manage. Q. 4, 357-379. doi: 10.1080/16184740500430215

Cohen, L., Manion, L., and Morrison, K. (2007). Research Methods in Education, 6th Edn. London: Routledge.

Cushion, C., and Jones, R. L. (2006). Power, discourse, and symbolic violence in professional youth soccer: the case of Albion Football Club. Sociol. Sport J. 23, 142-161. doi: $10.1123 /$ ss..23.2.142

Daiute, C., and Lightfoot, C. (2004). Narrative Analysis: Studying the Development of Individuals in Society. Thousand Oaks, CA: Sage. doi: $10.4135 / 9781412985246$

Donnelly, P. (1997). Child labour, sport labour: applying child labour laws to sport. Int. Rev. Sociol. Sport 32, 389-406. doi: 10.1177/101269097032004004

Ennis, C. (2017). Educating students for a lifetime of physical activity: enhancing mindfulness, motivation, and meaning. Res. Q. Exerc. Sport 88, 241-250. doi: $10.1080 / 02701367.2017 .1342495$

Evans, M. B., Allan, V., Erickson, K., Martin, L. J., Budziszewski, R., and Côté, J. (2017). Are all sport activities equal? A systematic review of how youth psychosocial experiences vary across differing sport activities. Br. J. Sports Med. 51, 169-176. doi: 10.1136/bjsports-2016-096725

George, M. L., and Curtner-Smith, M. D. (2016). Parents' reading of and expectations for physical education. Res. Q. Exerc. Sport 87, 106.

Gilbert, W., Gallimore, R., and Trudel, P. (2009). A learning community approach to coach development in youth sport. J. Coach. Educ. 2, 3-23. doi: $10.1123 /$ jce.2.2.3

Gilbert, W. D., and Trudel, P. (2001). Learning to coach through experience: Reflection in model youth sport coaches. J. Teach. Phys. Educ. 21, 16-34. doi: $10.1123 /$ jtpe.21.1.16

Jeffs, T., and Smith, M. K. (2005). Informal Education: Conversation. Democracy and Learning, 3rd Edn. Nottingham: Educational Heretics Press.

Kirk, D. (2005). Physical education, youth sport and lifelong participation: the importance of early learning experiences. Eur. Phys. Educ. Rev. 11, 239-255. doi: $10.1177 / 1356336 \times 05056649$

Kirk, D. (2006). Sport education, critical pedagogy, and learning theory: toward an intrinsic justifi cation for physical education and youth sport. Quest 58, 255-264. doi: 10.1080/00336297.2006.10491882

Knight, C. J., and Holt, N. L. (2014). Youth sport parenting practices, parenting styles, emotional climate psychology of sport \& exercise. J. Psychol. Sport Exerc. 15, 155-164. doi: 10.1016/j.psychsport.2013.10.010

Kolt, G. S., and Kirkby, R. J. (1996). "Reasons for participation in and dropout from gymnastics in Australia," in Proceedings of the Australian Conference of Science and Medicine in Sport (Canberra, ACT), 230-231.

Krueger, R. A. (1988). Focus Groups: A Practical Guide for Applied Research. Beverley Hills, CA: Sage.

Lemyre, F., Trudel, P., and Durand-Bush, N. (2007). How youth-sport coaches learn to coach. Sport Psychol. 21, 191-209. doi: 10.1123/tsp.21.2.191

Lesyk, J., and Kornspan, A. (2000). Coaches' expectations and beliefs regarding benefits of youth sport participation. Percept. Motor Skills 90, 399-402. doi: $10.2466 /$ pms.2000.90.2.399
Light, R., Harvey, S., and Memmert, D. (2013). Why children join and stay in sports clubs: Case studies in Australian, French and German swimming clubs. Sport Educ. Soc. 18, 550-566. doi: 10.1080/13573322.2011.594431

McCallister, S. G., Blinde, E. M., and Weiss, W. M. (2000). Teaching values and implementing philosophies: dilemmas of the youth sport coach. Phys. Educ. 57:35.

Morgan, D. L. (1988). Focus Groups as Qualitative Research. Beverley Hills, CA: Sage.

Morgan, D. L. (1997). The Focus Group Guidebook, Vol. 1. Beverley Hills: Sage Publications. doi: $10.4135 / 9781483328164$

$\mathrm{Na}$, J. (2015). Parents' perceptions of their children's experiences in physical education and youth sport. Phys. Educ. 72:139.

Partridge, J., and Wann, D. (2015). Exploring the shame coping experiences of youth sport parents. J. Sport Behav. 38:288.

Penney, D. (2006). "Coaching as teaching: new acknowledgments in practice," in The Sports Coach as Educator (London: Routledge), 43-54.

Quennerstedt, M., Öhman, M., and Armour, K. (2014). Sport and exercise pedagogy and questions about learning. Sport Educ. Soc. 19, 885-898. doi: 10.1080/13573322.2013.847824

Reeve, J. (2009). Why teachers adopt a controlling motivating style toward students and how they can become more autonomy supportive. Educ. Psychol. 44, 159-175. doi: 10.1080/00461520903028990

Robson, C (2002). Real World Research, 2nd Edn. Oxford: Blackwell.

Romar, J. E., Sarén, J., and Hastie, P. (2016). Athlete-Centred coaching using the Sport Education model in youth soccer. J. Phys. Educ. Sport 16, 380-391.

Saunders, W. M., Goldenberg, C. N., and Gallimore, R. (2009). Increasing achievement by focusing grade-level teams on improving classroom learning: a prospective, quasi-experimental study of title I schools. Am. Educ. Res. J. 46, 1006-1033. doi: $10.3102 / 0002831209333185$

Shaikh, M., and Forneris, T. (2018). The influence of junior coaches on club members in the Start2Finish Running \& Reading Club: a qualitative study. J. Adolesc. 68, 50-60. doi: 10.1016/j.adolescence.2018.07.004

Somekh, B., and Lewin, C. (2005). Research Methods in the Social Sciences. London: Sage.

Sport England (2016). Towards and Active Nation.

Stafford, I. (2011). Coaching Children in Sport. New York, NY: Routledge. doi: $10.4324 / 9780203850688$

Stewart, O. G., and Jordan, M. E. (2017). "Some explanation here": a case study of learning opportunities and tensions in an informal science learning environment. Instr. Sci. 45:137. doi: 10.1007/s11251-016-9396-7

Tharani, A., Husain, Y., and Warwick, I. (2017). Learning environment and emotional well-being: a qualitative study of undergraduate nursing students. Nurse Educ. Td. 59, 82-87. doi: 10.1016/j.nedt.2017.09.008

Whatman, S. L., and Main, K. (2018). Re-engaging 'youth at risk' of disengaging from schooling through rugby league club partnership: unpacking the pedagogic practices of the Titans Learning Centre. Sport Educ. Soc. 23, 339-353. doi: 10.1080/13573322.2016.1184135

Wright, T., Trudel, P., and Culver, D. (2007). Learning how to coach: the different learning situations reported by youth ice hockey coaches. Phys. Educ. Sport Pedagogy 12, 127-144. doi: 10.1080/17408980701282019

Conflict of Interest: The authors declare that the research was conducted in the absence of any commercial or financial relationships that could be construed as a potential conflict of interest.

Copyright $\odot 2019$ Littlefair and Nichol. This is an open-access article distributed under the terms of the Creative Commons Attribution License (CC BY). The use, distribution or reproduction in other forums is permitted, provided the original author(s) and the copyright owner(s) are credited and that the original publication in this journal is cited, in accordance with accepted academic practice. No use, distribution or reproduction is permitted which does not comply with these terms. 